\title{
In vitro anti-inflammatory activity of aqueous, ethanolic and ethereal extracts of rhizomes, leaves and stems of Anredera vesicaria
}

\begin{abstract}
Anredera vesicaria has been used traditionally in the eastern region of Cuba to treat various inflammatory conditions. No reports of the anti-inflammatory activity of this species have been published so far. The aim of this study was to determine the in vitro anti-inflammatory activity of the aqueous, ethanolic and ethereal extracts of the leaves, stems and rhizomes of the A. vesicaria. Serial dissolutions were prepared at 125,250 and $500 \mu \mathrm{g} / \mathrm{mL}$ from each dry extract of the plant parts, which were subjected to determinations of the anti-inflammatory activity in vitro by Human Red Blood Cell (HRBC) membrane stabilization method, using diclofenac sodium as a reference drug. All extracts were able to stabilize the erythrocyte membrane in hypotonic solution and exhibited major activity than diclofenac sodium at different doses. The stems extracts showed the highest activity, which suggest a major concentration of compounds with potential anti-inflammatory activity.
\end{abstract}

Keywords: Anredera vesicaria, anti-inflammatory activity, human red blood cell membrane stabilization

\author{
Volume 7 Issue 4 - 2018
}

\author{
José Angel Morales León, ' Aliuska González \\ Santisteban, ${ }^{2}$ Dilver Peña Fuentes, 'Yans \\ Guardia Puebla, ${ }^{3}$ Eugenio Torres Rodríguez' \\ 'Center for Applied Chemistry Studies, University of Granma, \\ Cuba \\ ${ }^{2}$ Celia Sánchez Manduley, Clinical Surgical Hospital, Cuba \\ ${ }^{3}$ Department of Mechanical Engineering, University of Granma, \\ Cuba
}

Correspondence: José Angel Morales León, Center for Applied Chemistry Studies, University of Granma, Cuba, Email imorales@udg.co.cu

Received: March 19, 2018| Published: August 13, 2018

\section{Introduction}

Inflammation can occur when viruses or infectious microorganisms such as bacteria and fungi, invade the body, also in response to tissue injuries, cell death, cancer, ischemia, and degeneration. Innate immune and adaptive immune responses are involved in the formation of inflammation. Both are defense mechanisms against invasive pathogens and cancerous cells.,

The use of plants, their parts and extracts as anti-inflammatory is widespread in several geographical areas. In the east of Cuba the rhizomes of $A$. vesicaria (yuca hiedra) are used to treat inflammatory conditions caused by blows, fractures, wounds and other painful traumas. ${ }^{3}$ No reports of the anti-inflammatory activity of this species have been published so far. Recent studies show that $A$. vesicaria contains sterols, phenols, flavonoids, coumarins, alkaloids, triterpenes, mucilages and saponins. ${ }^{4}$ Some of these metabolites could be related with the anti-inflammatory activity ascribable to this plant. The aim of this study was to determine the in vitro anti-inflammatory activity of the aqueous, ethanolic and ethereal extracts of the leaves, rhizomes and stems of $A$. vesicaria.

\section{Materials and methods}

\section{Plant material}

The plant A. vesicaria was collected in the neighborhood Gutiérrez, in Manzanillo municipality, Granma Province, Cuba and authenticated in the herbarium of Botanical Garden Cupainicú located in Guisa municipality. The leaves, rhizomes and stems of the plant were dried at ambient temperature under shade for 7 days and the drying process was continued in a drying chamber under air recirculation at $38^{\circ} \mathrm{C}$. The dried material was ground till a fine degree (particle diameter $<1.0 \mathrm{~mm}$ ) using a laboratory scale mill.

\section{Extraction}

The powdered plant materials (rhizomes, leaves and stems) were extracted separately with diethyl ether, $70 \%$ ethanol and distilled water using an ultrasonic bath at $20 \mathrm{kHz}$ and $25^{\circ} \mathrm{C}$ for 2 hours. The extracts were concentrated until dryness under reduced pressure using a rotary evaporator at $40^{\circ} \mathrm{C}$ and stored in fridge at $4{ }^{\circ} \mathrm{C}$ for future use. All the reagents and solvents used were of analytical grade and proceeded from Merck.

\section{In vitro anti-inflammatory activity}

The anti-inflammatory activity of the extracts was determined using human red blood cell (HRBC) - membrane stabilization assay developed by Shinde et al. ${ }^{5}$ and modified by Sikder et al. ${ }^{6}$ Venous human blood was collected from a normal female adult who had not consumed anti-inflammatory or contraceptive medicaments during two weeks before taking the sample. The blood was mixed with equal volume of Alsever's solution ( $2 \%$ dextrose, $0.8 \%$ sodium citrate, $0.05 \%$ citric acid and $0.42 \%$ sodium chloride in water). The resulting mixture was centrifuged at $3000 \mathrm{rpm}$ for $10 \mathrm{~min}$; the supernatant was removed and the packed cells washed 3 times with isosaline solution $(0.9 \%, \mathrm{pH} 7.2)$. The assay mixture was prepared by mixing $1 \mathrm{~mL}$ phosphate buffer ( $\mathrm{pH} 7.4), 2 \mathrm{~mL}$ hyposaline solution $(0.36 \%)$ and $0.5 \mathrm{~mL}$ HRBC suspension $(10 \% \mathrm{v} / \mathrm{v})$ with $1 \mathrm{~mL}$ of each plant extracts of various concentrations $(125,250$ and $500 \mu \mathrm{g} / \mathrm{mL})$ or standard drug diclofenac sodium $(125,250$ and $500 \mu \mathrm{g} / \mathrm{mL})$, respectively. A reaction mixture with distilled water instead of plant sample was used as control and phosphate buffer as blank. The mixtures were incubated at $37^{\circ} \mathrm{C}$ for 30 minutes and then centrifuged at 3000rpm. The hemoglobin content in the supernatant solution was estimated spectrophotometrically at $560 \mathrm{~nm} .12$ treatments with three replicates were applied. The percentage of hemolysis produced in the presence of distilled water was considered as $100 \%$. The percentage of HRBC membrane stabilization was calculated using the formula: 


$$
\text { Percentage of stabilization }=\frac{A b s(\text { Control })-\text { Abs }(\text { Sample })}{A b s(\text { Control })} \times 100
$$

\section{Statistical analysis}

The results were processed using the statistical package Statgraphics Centurion XV. A factorial design was used, where the effects of the $i^{\text {th }}$-levels of several quantitative factors and their interactions on the interest responses were studied. The variables representing the evaluated factors were: extracts $(\tau)$, doses $(\beta)$ and plant parts $(\gamma)$; while the other parameters of the model characterized the effect of the interactions between both factors.

$$
y_{i j k l}=\mu+\tau_{i}+\beta_{i}+\gamma_{i}+(\tau \beta \gamma)_{i j}+\grave{o}_{i j k l}\left\{\begin{array}{c}
i=1,2,3,4 \\
j=1,2,3
\end{array}\right.
$$

The levels of the factors were defined as follows: 3 types of extracts (water, ethanol and diethyl ether), 3 levels of doses (125, 250 and $500 \mu \mathrm{g} / \mathrm{mL}$ ) and 3 plant parts (leaves-, stems- and rhizomes-extracts) together with diclofenac sodium. Statistical analysis was performed using an analysis of variance (ANOVA). The F-test value was calculated and a $p$ value $<0.05$ was considered statistically significant.

\section{Results and discussion}

During inflammation the lysosomal enzymes are released and several typical alterations may occur. ${ }^{7}$ Stabilization of the lysosomal membrane prevents chemical mediators and lysosomal components of activated neutrophils from releasing, which limits inflammatory process. ${ }^{8}$ This is the mechanism of action of many anti-inflammatory agents. ${ }^{9,10}$ The erythrocyte and lysosome membranes are rather similar, so that the erythrocyte membrane stabilization could be extrapolated to the stabilization of lysosomal membrane.

We have evaluated the effect of aqueous, ethanolic and ethereal extracts obtained from different plant organs of A. vesicaria on stabilization of HRBC membrane. It was found that all extracts at different concentrations have the ability to stabilize the RBC membrane in hypotonic solution and to inhibit the hemolysis. Aqueous extracts of leaves and stems showed the highest percentage of inhibition at $500 \mu \mathrm{g} / \mathrm{mL}$ with $75.52 \%$ and $77.34 \%$, respectively, without significant difference between them. The activity of aqueous extract prepared from rhizomes at $500 \mu \mathrm{g} / \mathrm{mL}$ was significantly lower. Nevertheless all aqueous extracts exhibited higher activity than standard diclofenac sodium. This difference was more pronounced for stem extract at $125 \mu \mathrm{g} / \mathrm{mL}$ (Table 1).

\begin{tabular}{|c|c|c|c|c|}
\hline \multirow{2}{*}{ Plant parts } & \multirow{2}{*}{ Extracts } & \multicolumn{3}{|c|}{ \% Stabilization on HRBC membrane ( $X \pm D S$ ) } \\
\hline & & $125 \mu \mathrm{g} / \mathrm{mL}$ & $250 \mu \mathrm{g} / \mathrm{mL}$ & $500 \mu g / m L$ \\
\hline & $\mathrm{Aq}$ & $19.53 \pm 1.28$ & $61.72 \pm 1.69$ & $75.52 \pm 2.42$ \\
\hline \multirow{3}{*}{ Leaves } & $\mathrm{EtOH}$ & $19.69 \pm 3.91$ & $52.49 \pm 0.37$ & $70.34 \pm 3.17$ \\
\hline & $\mathrm{Et}_{2} \mathrm{O}$ & $42.45 \pm 3.15$ & $59.11 \pm 1.47$ & $69.53 \pm 3.55$ \\
\hline & $\mathrm{Aq}$ & $55.99 \pm 0.97$ & $69.01 \pm 0.97$ & $77.34 \pm 0.64$ \\
\hline \multirow{3}{*}{ Stem } & $\mathrm{EtOH}$ & $51.97 \pm 1.29$ & $59.58 \pm 1.34$ & $74.28 \pm 3.17$ \\
\hline & $\mathrm{Et}_{2} \mathrm{O}$ & $53.65 \pm 0.97$ & $66.15 \pm 5.35$ & $82.03 \pm 2.21$ \\
\hline & $\mathrm{Aq}$ & $21.88 \pm 1.28$ & $52.60 \pm 5.40$ & $70.57 \pm 3.63$ \\
\hline \multirow{2}{*}{ Rhizomes } & $\mathrm{EtOH}$ & $19.85 \pm 5.34$ & $56.23 \pm 3.76$ & $70.23 \pm 3.82$ \\
\hline & $\mathrm{Et}_{2} \mathrm{O}$ & $50.00 \pm 2.92$ & $67.97 \pm 0.78$ & $67.45 \pm 4.30$ \\
\hline \multicolumn{2}{|c|}{ Control (Diclofenac sodium) } & $22.40 \pm 0.97$ & $33.07 \pm 5.72$ & $51.56 \pm 3.88$ \\
\hline
\end{tabular}

Table I Anti-inflammatory activity of aqueous, ethanolic and ethereal extracts of A. vesicaria

Abbreviations Aq, aqueous; EtOH, ethanolic; Et2O, ethereal

A similar effect was observed for the ethanolic extracts; all of them showed major activity than standard diclofenac sodium at 250 and $500 \mu \mathrm{g} / \mathrm{mL}$. At $125 \mu \mathrm{g} / \mathrm{mL}$ only the stem extract exhibited a remarkable inhibition of the RBC membrane hemolysis (Table 1). The maximum percentage stabilization among all extracts was observed for the stem ethereal extract $(82.03 \%)$ at $500 \mu \mathrm{g} / \mathrm{mL}$ (Table 1). These results are comparable with the anti-inflammatory activity found in other plants of the same genus. ${ }^{11}$ The membrane stabilizer effect could be attributed to the presence of oleanolic acid, ${ }^{4}$ a triterpenoid with proved wound-healing ${ }^{12}$ and anti-inflammatory properties. ${ }^{13-15}$

The quantitative factors studied and their interactions on the interest responses were also studied (Figure 1). When the doses increased, the percentage of stabilization also increased. The highest percentage of stabilization of HRBC membrane was obtained at $500 \mu \mathrm{g} / \mathrm{mL}$. Interestingly the ethereal extracts at $125 \mu \mathrm{g} / \mathrm{mL}$ showed a notable anti-inflammatory activity that was statistically significant in comparison with the aqueous and ethanolic extracts (Figure 1A). The extracts prepared from all plant parts have shown higher percentages of stabilization than diclofenac sodium and those obtained from stem in water and diethyl ether exhibited statistically greater activities (Figure 1B). When we compared the percentages of stabilization of all plant extracts and diclofenac sodium at 125,250 and $500 \mu \mathrm{g} / \mathrm{mL}$, we found that stem extracts showed statistically significant higher anti-inflammatory activity (Figure 1C). Although the rhizomes are the most widespread used plant part, ${ }^{3}$ the stems of $A$. vesicaria show higher activity, which suggest a major concentration of compounds with potential anti-inflammatory activity.

The analysis of variance (ANOVA) was conducted to study the significance of the 3 factors (extracts, doses and plant parts/diclofenac sodium) over the variable responses for the experimental data 
obtained. The results obtained for various treatment combinations using ANOVA are summarized in Table 2. Significant differences among all the factors and significant interactions among the evaluated levels were detected. These results show the influence of the 3 factors on the stabilization of HRBC membrane.

Table 2 Analysis of variance (ANOVA)

\begin{tabular}{llllll}
\hline Source & $\begin{array}{l}\text { Sum of } \\
\text { squares }\end{array}$ & Df & Mean square & F-ratio & P-value \\
\hline Main effects & & & & & \\
A:Extract & 798,344 & 2 & 399,172 & 14,46 & $0,0000^{*}$ \\
B:Dose & 21078,6 & 2 & 10539,3 & $38 \mid, 87$ & $0,0000^{*}$ \\
C:Product & 11628,9 & 3 & 3876,29 & 140,45 & $0,0000^{*}$ \\
Interactions & & & & & \\
AB & 698,964 & 4 & $|74,74|$ & 6,33 & $0,0002^{*}$ \\
AC & 861,305 & 6 & $|43,55|$ & 5,20 & $0,000 I^{*}$ \\
BC & 1987,81 & 6 & $33|, 30|$ & 12,00 & $0,0000^{*}$ \\
Residual & 2318,34 & 84 & 27,5993 & & \\
Total & 39372,2 & 107 & & & \\
(Corrected) & & & & & \\
\hline
\end{tabular}

*p-value $<0.05$ was considered as statistically significant
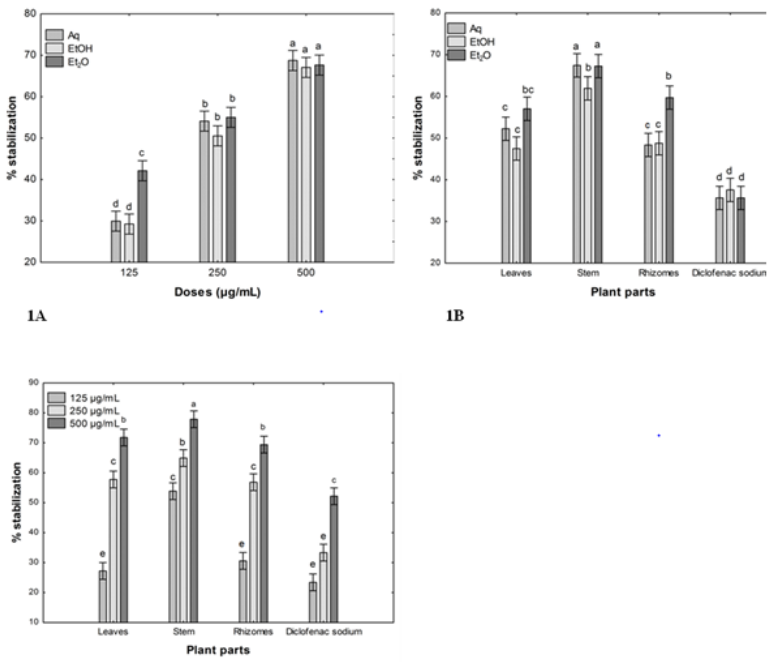

$1 \mathrm{C}$

Figure I Statistically significant interactions between the plant parts, doses and extracts with the percentage of membrane stabilization: IA) extracts vs. doses; IB) extracts vs. plant parts; IC) doses vs. plant parts/diclofenac sodium.

\section{Conclusion}

This work represents the first report of the anti-inflammatory activity of $A$. vesicaria by HRBC membrane stabilization method. All evaluated extracts exhibit major activity than diclofenac sodium at different doses. The stems extracts showed the highest activity, which suggest a major concentration of compounds with potential antiinflammatory activity.

\section{Acknowledgements}

We thank the German Academic Exchange Service (DAAD) for the technical support and material provided in conducting this research.

\section{Conflict of interest}

The author declares that there is not conflict of interest.

\section{References}

1. Isailovic N, Daigo K, Mantovani A, et al. Interleukin-17 and innate immunity in infections and chronic inflammation. $J$ Autoimmun. 2015;60:1-11

2. Waisman A, Liblau RS, Becher B. Innate and adaptive immune responses in the CNS. Lancet Neurol. 2015;14(9):945-955.

3. Roig Mesa JT. Diccionario botánico de nombres vulgares cubanos. 2nd edition. Cuba: Editorial Científico-Técnica; 1998: 1142 p.

4. De la Cruz Frías M, Torres Rodríguez E, Morales León JA, et al. Identificación de metabolitos secundarios de Anredera vesicaria (Yuca hiedra). Rev Cub Plant Med. 2016;21(2):215-222.

5. Shinde UA, Phadke AS, Nair AM, et al. Membrane stabilizing activity-a possible mechanism of action for the anti-inflammatory activity of Cedrus deodara wood oil. Fitoterapia. 1999;70(3):251-257.

6. Sikder MA, Rahman MA, Kaisar MA, et al. In vitro Antioxidant, reducing power, free radical scavenging and membrane stabilizing activities of seeds of Syzygium cumini L. Lat Am J Pharm. 2011;30:781-785.

7. Ashtari N, Jiao X, Rahimi-Balaei M, et al. Lysosomal Acid Phosphatase Biosynthesis and Dysfunction: A Mini Review Focused on Lysosomal Enzyme Dysfunction in Brain. Curr Mol Med. 2016;16(5):439-446.

8. Abdelkader B, Tighzert S, Ibelhoulen N, et al. In-vitro Antioxidant and Anti-Inflammatory Activities of Peel and Peeled Fruits Citrus limon. Current Nutrition \& Food Science. 2016;12(4):279-287.

9. Chowdhury A, Azam S, Jainul MA, et al. Antibacterial activities and in vitro anti-inflammatory (membrane stability) properties of methanolic extracts of Gardenia coronaria leaves. Int J Microbiol. 2014:410935.

10. Vane JR, Botting RM. New insight into the mode of action of antiinflammatory drugs. Inflamm Res. 1995;44(1):1-10.

11. Sutrisno E, Adnyana IK, Sukandar EY, et al. Anti-inflammatory study of Anredera cordifolia leaves and Centella asiatica herbs and its combinations using human red blood cell-membrane stabilization method. Asian $J$ Pharm Clin Res. 2016;9(5):78-80.

12. Moura-Letts G, Villegas LF, Marçalo A, et al. In vivo wound-healing activity of oleanolic acid derived from the acidhydrolysis of Anredera diffusa. J Nat Prod. 2006;69(6):978-979.

13. Sultana N, Ata A. Oleanolic acid and related derivatives as medicinally important compounds. J Enzyme Inhib Med Chem. 2008;23(6):739-756.

14. Azab A, Nassar A, Azab AN. Anti-Inflammatory Activity of Natural Products. Molecules. 2016;21(10):1321.

15. Lais C Agra, Jamylle NS Ferro, Fabiano T Barbosa, et al. Triterpenes with healing activity: A systematic review. J Dermatolog Treat. 2015;26(5):465470 